\title{
A new system of deployable structures with reciprocal linkages for emergency buildings
}

\author{
J. Pérez-Valcárcel, M. Muñoz-Vidal, F. Suárez-Riestra, Isaac R. López-César, M. J. \\ Freire-Tellado
}

Grupo de Estructuras Arquitectónicas (GEA). Estructuras singulares (GES)

Dpto. de Tecnología de la Construcción.

Escuela Técnica Superior de Arquitectura.

Universidade da Coruña. Campus de A Coruña

SPAIN

\begin{abstract}
Deployable structures are a good solution for emergency buildings, due to their lightness and compact nature which means they can be transported to where they are needed. Nevertheless, the deployable structures studied to date have the drawback of being too deformable, so that larger and therefore heavier sections had to be used. This paper proposes a new type of deployable structure that uses reciprocal linkages which give rise to greater strength and rigidity. The geometrical and mechanical conditions of the linkages are analysed, as several different types which perform better can be designed, and a calculation method is developed to analyse structures of this type. The features and behaviour of a flat mesh with articulated reciprocal linkages are also compared analytically and experimentally. The theoretical calculations and experimental tests make it possible to prove the viability and efficacy of this new structural type.
\end{abstract}

Keywords: Expandable structures; reciprocal linkages; lightweight structures; temporary buildings; emergency buildings.

\section{Introduction}

A natural disaster may occur at any time in any society, regardless of its degree of development. This is the greatest potential risk, given that other possible catastrophic situations such as armed conflict are more localised in space and time, even though they may be more destructive. These catastrophes leave thousands of people without shelter, with severe risks for their health and coexistence. It is extremely important to design valid solutions to help people in these situations. In the field of architecture the design of solutions for the populations involved is especially relevant, in order to provide them with the services they need.

The first structures of this type were developed by the Spanish architect Emilio Pérez Piñero, using modules of bars [1, 2]. These modules are composed of three or four bars joined at a central point. Pérez Piñero was the author of the first large deployable structure built, the pavilion of the XXV Years of Peace Exhibition in 1964. This was firstly deployed in Madrid, after which it was taken to Barcelona and San Sebastián (figure 1) [3]. 


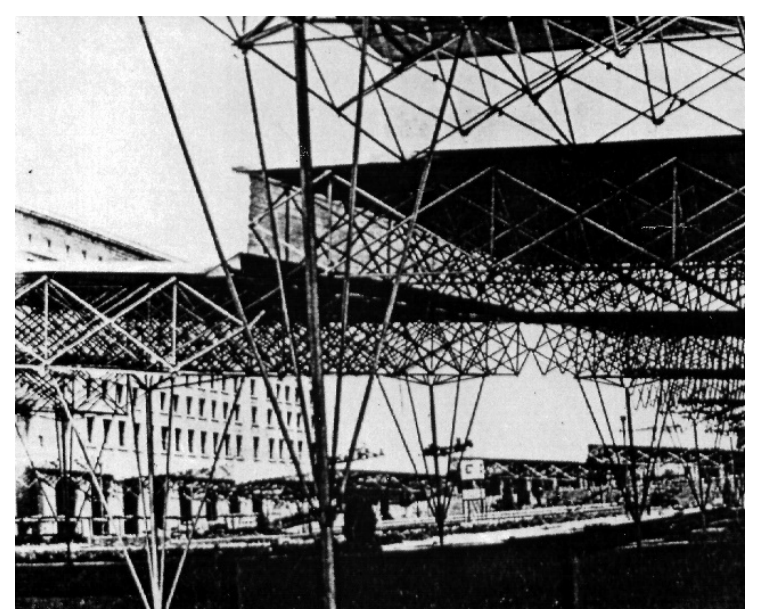

Figure 1.- Transportable Pavilion by E. P. Piñero in Madrid [photo courtesy of E. Pérez Belda]

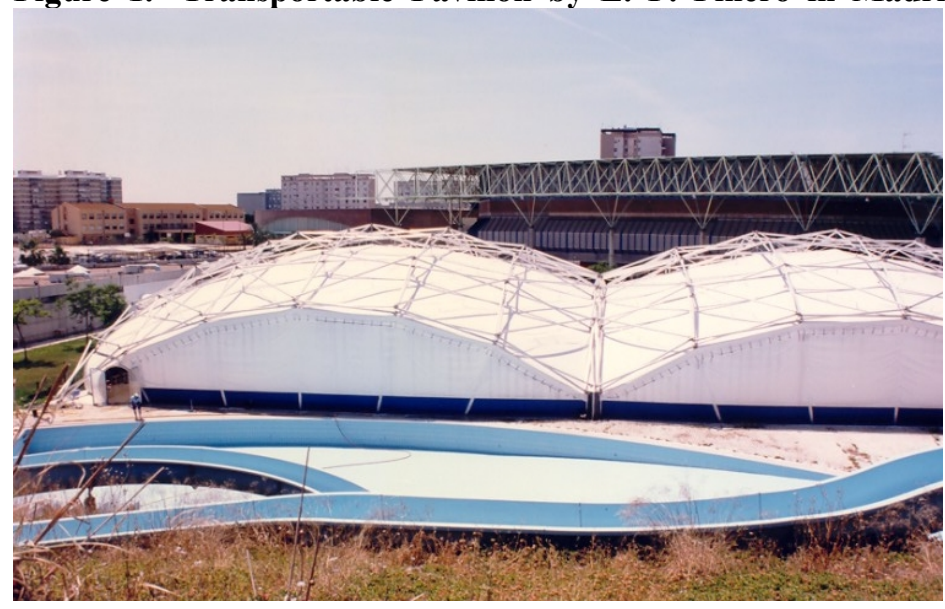

Figure 2.- San Pablo swimming pool.

In the 1980s and 1990s, important studies were made of deployable structures, such as the works by Escrig et al. in 1988 and 1999 [4, 5]; Pérez-Valcárcel et al. in 1987 and 1995 [6, 7]; Gantes et al. in 1991 [8] or Pellegrino in 2001 [9]. The latter works are focused on modules composed of scissor-like elements (SLE) with a triangular or square base. The lack of rigidity of the latter made a range of bracing solutions necessary, which resolved the problem but also created constructive difficulties. The most typical solutions were the installation of additional bars after deployment, or the design of bars with an internal lockable joint that were included in the bar package before deployment [10]. Few of these structures were put into practice, the most outstanding of which was San Pablo swimming pool in Seville, by Escrig, Sánchez and Valcárcel (Figure 2) [11].

Deployable structures have recently been the subject of numerous studies which analyse several of their elements. The works by Temmerman, Arnouts, Massart, and Berke [12, 13, 14] stand out, as do those by Gantes [15], Akgün [16], Alegria [17,18] Beguiristain [19], Maden [20], Osmani [21] and others. Studies of retractile solutions based on the diaphragm model have also been carried out, opening a roof outwards towards its perimeter (Hoberman, 1992) [22].

It has to be said that all deployable structures to date were designed and constructed using scissor-like elements with a gyratory interior linkage and joints at their ends. These joints were resolved using different types of linkages, but they always permit free turning of the end of the bar. The novelty of the system proposed in this paper consists of the linkage design, which makes deployment possible but also includes the advantages of reciprocal structures. This makes it possible to resolve some of the main problems of deployable structures, in particular their lack of rigidity when subjected to actions, which makes these structures highly deformable.

Reciprocal structures are designed in an attempt to resolve the problem of roofing a span with parts that are smaller than the same, without using intermediate supports. The idea is that the available parts support each other up to the desired size. This is an old constructive principle, and it may be found in medieval manuscripts, such as the one by Villard de Honnecourt, and manuscripts from the Renaissance, such as the Atlantic Codex by Leonardo da Vinci (Ponte Arcuato, sheet 899sx328) or the Seven Books of 
Architecture, by Serlio. These diagrams make it possible to define a basic pattern, making it possible to cover large surfaces, both flat and curved.

Meshes of this flat type function well structurally, according to studies of their strength behaviour (Choo et al. 2010, Sánchez el al. 2010) [23, 24]. In spite of this, the problem with these structures is that failure of one part may lead to the collapse of the complete structure. This problem is resolved if structures of this type are made using redundant connections. This idea can be seen in the drawing by Sebastian Serlio in Figure 3. In this case each part has more than two connections to its neighbours, so that if a section in one of them fails, the loads are easily distributed among its adjacent parts. The proposed linkages do in fact have the connections which correspond to deployable structures, so that alternative mechanisms always exist that are able to prevent failure.

Figure 4 shows a typical roofing solution resolved using a reciprocal structure. Several roofing solutions have been constructed using this pattern, such as those based on the system described by Popovič [25]

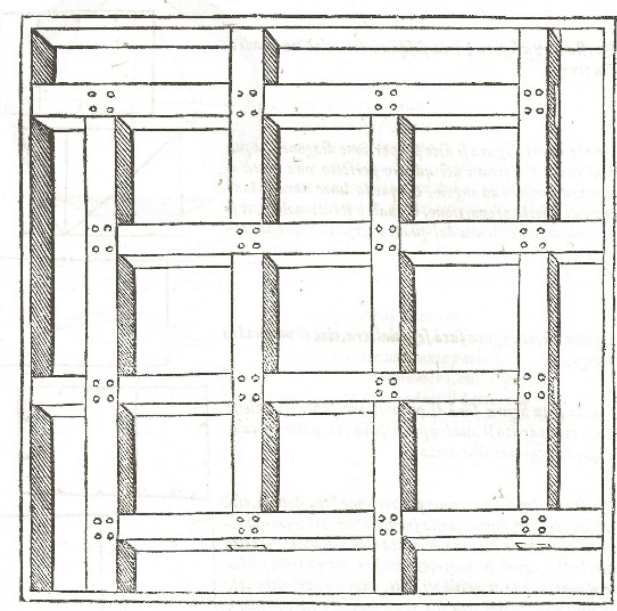

Figure 3.- Reciprocal structure (Serlio).

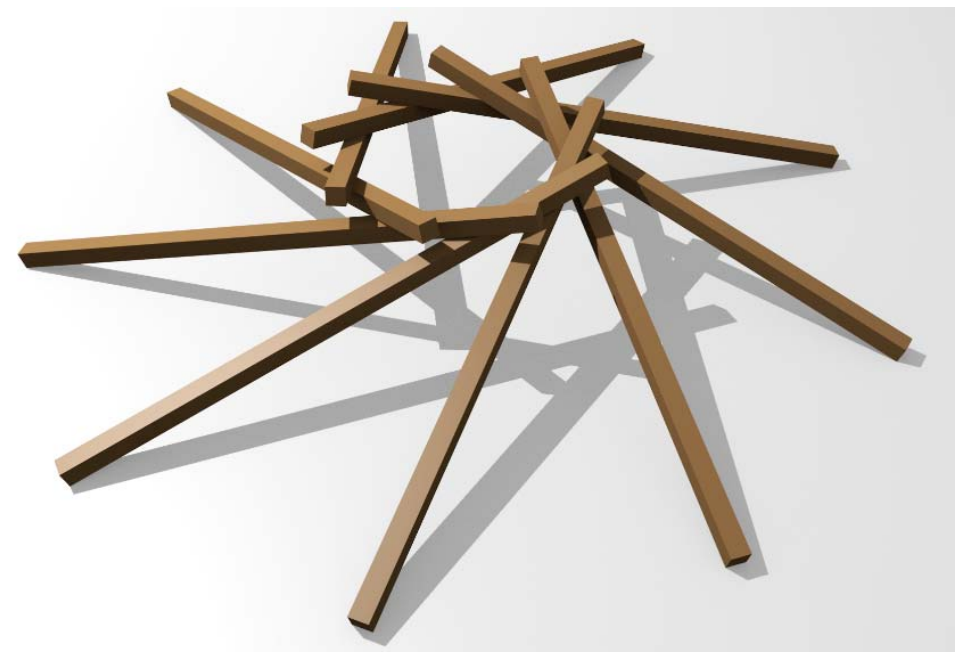

Figure 4.- Reciprocal roof structure.

Several attempts have been made to analyse the relationship between reciprocal and deployable structures. Their use as emergency shelters with reciprocal frames for simple fast construction has been studied, such as the proposal by Popovič et al. [26].

This paper centres on a synthesis of both structural types: deployable structures composed of scissor-like elements and reciprocal structures. It analyses a type of deployable structure which uses a new system that has major advantages over other solutions. Deployable structures are light and foldable, so they can be transported easily to where they are needed, to be deployed quickly and without the need for complicated resources.

A new and extremely simple type of linkage is proposed for this, in which the free turning of the end of the bar is constrained by the action of the other bars which join at the linkage. It entails the development and significant improvement of the one used in deployable structures such as the roof of the San Pablo pool, composed of a solid aluminium cylinder with two orthogonal pins (Figure 5). It is an effective linkage, but is quite heavy and expensive. In this paper a circular or square hollow section is proposed, this being lighter but equally strong, to which the bars are bolted laterally so that when they open they rest on each other to form a reciprocal structure (figure 6). It only uses cheap, simple elements such as hollow tube section, threaded rods, Teflon washers and nuts. Its effectiveness lies in the simple reciprocal support of the bars. 


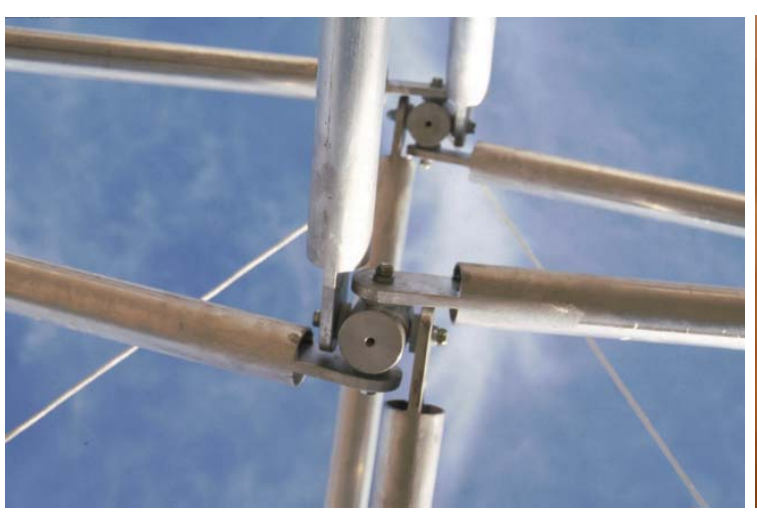

Figure 5.- Articulated linkages.

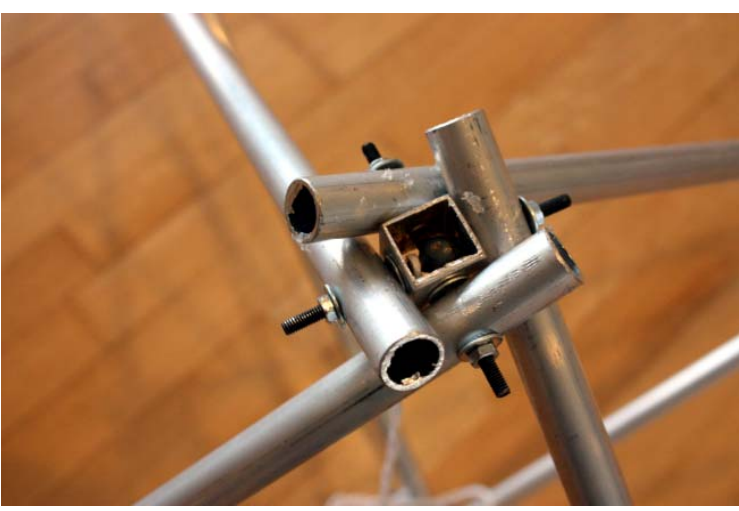

Figure 6.- Reciprocal linkage.

This arrangement means that the linkages at the ends of the bars cease to function in a simply articulated way and achieve rigidity close to embedment. This makes better use of the material, while considerably reducing displacements of the mesh. It also makes it possible to restrict the deployment of the structure until the bars are can turn no further on the linkage. At this point the structure is self-stabilising, with no need to add additional bars or new constraints by anchoring the structure to its supports. It also considerably simplifies the design of the linkages and the joint with the bars. The result is a structure that performs better and is also simpler and more economical. As the main problem with conventional deployable structures is their excessive deformability, the proposed system has undeniable advantages which are analysed in this paper.

A study of the previous works of the researchers mentioned in this paper shows that this type of structure has barely been developed to date. Only Pérez Piñero used a similar type of linkage in his module of bars, although this was solely used for the internal articulation of the bars. He always resolved exterior linkages by using articulated joints, which have been used habitually. In a recent study, Akgün et al. have proposed similar linkages to those of Pérez Piñero, but which are also only used for the central point [27]. The use of reciprocal linkages in extreme joints has recently been patented by Pérez-Valcárcel et al. [28].

To the best of our knowledge, no other architectural or civil engineering application of the deployable structure with reciprocal linkages concept exists today. Up to now, deployable structures have been based on connecting modules by means of articulated joints.

The objective of this contribution is to discuss the behaviour, both theoretical and experimental, of deployable structures of reciprocal linkages, in order to obtain a deep understanding of their structural response.

To do this, a matrix analysis model is developed, for which similar models have already been proposed in the literature. However, this model includes the necessary modifications to take into account the conditions of reciprocal support at the ends of the bars.

The originality of this paper centres on the following three aspects:

- the investigation of the geometrical and kinetic viability of deployable structures constructed using reciprocal linkages.

- the study of the mechanical conditions of the bars and their influence on the general behaviour of the structure.

- the investigation of the application of structures of this type to flat meshes.

The objective of the work is the structural response of deployable structures with reciprocal linkages and their practical applications. The reciprocal linkage system allows the design of more resistant and less deformable folding structures than conventional ones. It also allows the design of deployable structures that would be mechanisms without using reciprocal linkages. This involves opening a line of research relevant to future work.

From the initial definition, the geometric and compatibility conditions of the reciprocal nodes are analysed (Section 2). The influence of the embedment degree due to the reciprocal support of the knots is analysed using a matrix analysis that takes this effect into account (Section 3). The materials and methods used in the experimental analysis (Section 4) and the results obtained (Section 5) are described. Results are provided including the comparison between the results of the theoretical calculation and those obtained in the tests (Section 6). The conclusions and perspectives are presented in Section 7. 


\section{Description of deployable structures with reciprocal linkages.}

The novelty of this system lies in its use of reciprocal linkages composed of three bars in triangular meshes and four bars in square meshes. The bars pivot on horizontal axes which emerge from the linkage, which may take the form of a solid or hollow cylinder or prism (figure 6). The models used in this paper have four bars attached to a hollow square prism. Although it is possible to use stronger circular tubes in actual meshes, in smaller models it is simpler and more economical to use square tubes for the linkages. Both types perform in similar ways, although square linkages slightly constrain the bars laterally, which improves the rigidity of the assembly.

The use of the reciprocal joints means that the linkage has to be of minimum size which depends on the diameter of the bars and the desired angle of opening. To analyse the most general case, the bar opening angles are hypothesised to be different, $\alpha, \beta$, where $\mathbf{a}$ is the width of the linkage and $\mathbf{d}$ is the diameter of the bars which meet it, respectively.

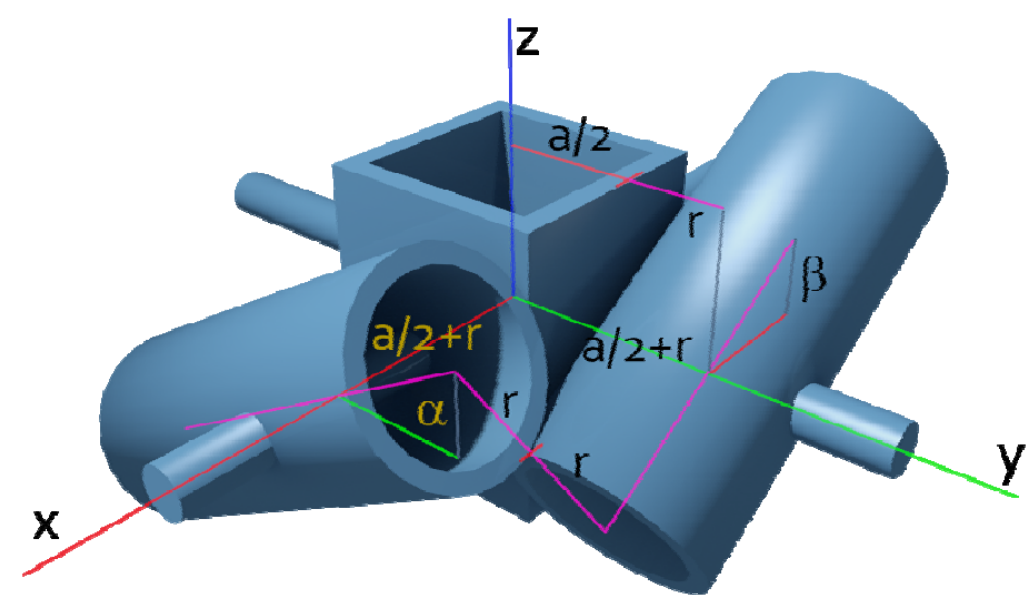

Figure 7.- Geometrical conditions of reciprocal linkages.

The separation between the axes of the bars may be determined by applying the condition that the distance between the two straight lines that cross is $d=2 r$, considering that the bars touch at the point of contact. The relationship between the width of the linkage $\mathbf{a}$ and that of the bar $\mathbf{d}$ is

$$
\frac{a}{d}=\frac{2 \cdot \sqrt{\sin ^{2} \alpha \cdot \cos ^{2} \beta+\cos ^{2} \alpha \cdot \sin ^{2} \beta+\cos ^{2} \alpha \cdot \cos ^{2} \beta}}{\sin (\alpha+\beta)}-1
$$

This equation makes it possible to determine the diameter or width that the linkage must have so that the bars form an reciprocal joint with specific angles of opening $\alpha$ and $\beta$. This is the most general case and the one which arises in cylindrical vaults. In flat meshes and regular domes both angles are the same. The formulas was simpler in this case, giving

$$
\frac{a}{d}=\frac{\sqrt{1+\sin ^{2} \alpha}}{\sin \alpha}-1
$$

To establish the mechanical conditions of the reciprocal linkages, it is necessary to calculate the distance between the pivot and the point at which one bar rests on another. These distances are 


$$
\begin{aligned}
& d\left(A_{1}, P_{1}\right)=\left(\frac{a+r}{2}\right) \frac{|\cos \alpha-\sin \alpha \cdot \sin \beta \cdot \cos \beta|}{1-\sin ^{2} \alpha \cdot \sin ^{2} \beta} \\
& d\left(A_{2}, P_{2}\right)=\left(\frac{a+r}{2}\right) \frac{|\cos \beta-\sin \alpha \cdot \sin \beta \cdot \cos \alpha|}{1-\sin ^{2} \alpha \cdot \sin ^{2} \beta}
\end{aligned}
$$

The deployable structures most widely used in practice are cylindrical and spherical meshes. If reciprocal linkages are used then flat meshes may also be created. In flat meshes deployable structures of articulated linkages are hardly useful due to the major deformations they undergo. On the other hand, with reciprocal linkages far less deformation occurs, as will be shown.

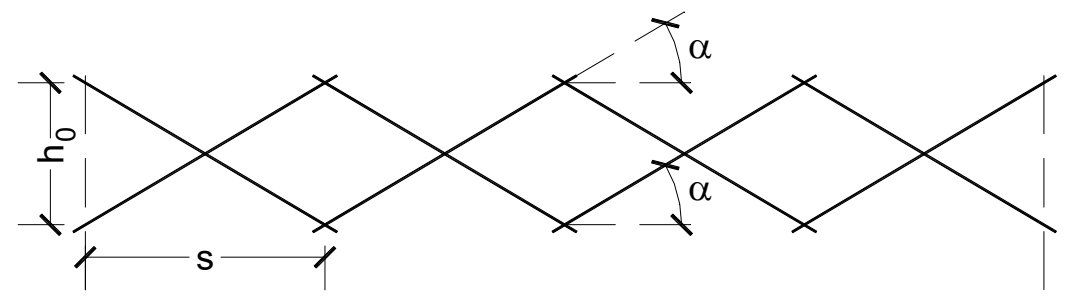

Figure 8.- General conditions for reciprocal flat meshes.

In the case of flat meshes the geometrical relationships are very simple. If $\mathbf{s}$ is the horizontal dimension of the module and $\mathbf{h}_{0}$ is the height following deployment, it is easy to calculate the angle $\alpha$ and the width of linkage that is necessary (Figure 8).

$$
\alpha=\arctan \frac{\mathrm{h}_{0}}{\mathrm{~s}} \quad ; \quad a=\left(\frac{\sqrt{1+\sin ^{2} \alpha}}{\sin \alpha}-1\right) \cdot d
$$

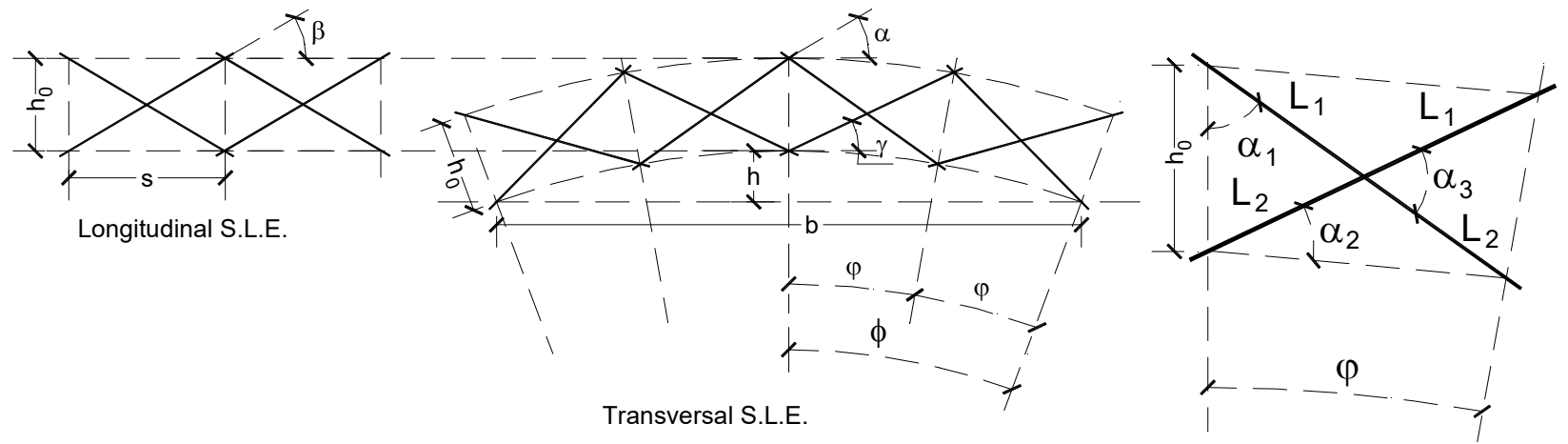

Figure 9.- Geometrical conditions for reciprocal cylindrical meshes.

In the case of curved meshes it is generally better to define them by their span $\mathbf{b}$, their height $\mathbf{h}$ and the desired angle $\mathbf{h}_{\mathbf{0}}$ (Figure 9). The geometrical conditions are

$$
h=r-r \cos \phi \quad ; \quad b=2 r \sin \phi
$$

Giving

$$
r=\frac{b^{2} / 4+h^{2}}{2 h} \quad ; \quad \phi=\arcsin \frac{b \cdot h}{b^{2} / 4+h^{2}} \quad ; \quad \varphi=\frac{\phi}{n}
$$

Where $\mathrm{n}$ is the number of semi-arch modules

It is now necessary to calculate the bar lengths. We can firstly calculate the total length, and then the length of the sections. Applying the triangle cosine rule gives 


$$
\begin{aligned}
& L^{2}=r^{2}+\left(r+h_{0}\right)^{2}-2 L\left(r+h_{0}\right) \cdot \cos \alpha_{1} \\
& \cos \alpha_{1}=\frac{L^{2}+\left(r+h_{0}\right)^{2}-r^{2}}{2 L\left(r+h_{0}\right)}
\end{aligned}
$$

As $\alpha_{2}=\frac{\pi}{2}-\left(\varphi+\alpha_{1}\right)$ the lengths of both sections of the bar will be

$$
\begin{aligned}
& \mathrm{L}_{1}=\frac{\mathrm{L} \cdot \cos \alpha_{2}}{\sin \alpha_{1}+\cos \alpha_{2}} ; \quad \mathrm{L}_{2}=\frac{\mathrm{L} \cdot \sin \alpha_{1}}{\sin \alpha_{1}+\cos \alpha_{2}} \\
& \alpha_{1}=\arccos \frac{\mathrm{L}_{1}^{2}-\mathrm{L}_{2}^{2}+\mathrm{h}_{0}^{2}}{2 \cdot \mathrm{h}_{0} \cdot \mathrm{L}_{1}} \quad ; \quad \alpha_{2}=\arccos \frac{\mathrm{L}_{2}^{2}-\mathrm{L}_{1}^{2}+\mathrm{h}_{0}{ }^{2}}{2 \cdot \mathrm{h}_{0} \cdot \mathrm{L}_{2}} \\
& \alpha=\pi / 2-\alpha_{1} \quad ; \quad \beta=\arcsin \left(\mathrm{h}_{0} / \mathrm{L}\right) \quad ; \quad \mathrm{s}=\mathrm{h}_{0} \cdot \cot \beta
\end{aligned}
$$

In general, in curved deployable structures which are useful in practice, reciprocal support conditions depend on the position of the linkages. In the upper layer the angles of the bars with the plane of the linkage are large, favouring reciprocal support with small linkage diameters. On the contrary, the linkages in the lower layer form small angles, so that the condition of reciprocal support would require largediameter linkages. These linkages would be far too large and this would create major and therefore totally unsuitable load eccentricities. It is therefore proposed to construct simple articulated linkages for the lower layer.

The two most widely used curved surfaces in deployable structures are sail domes and cylindrical vaults. The linkage design is different in both cases.

In the case of sail domes (Figure 10), the curvature is the same in both directions. The angle of the upper layer is $\alpha$ and as a result of this the diameter of the linkage may be calculated by the above formula [2]. If the dome is strongly angled the angular distortion of the modules may require the use of rhomboid linkages.

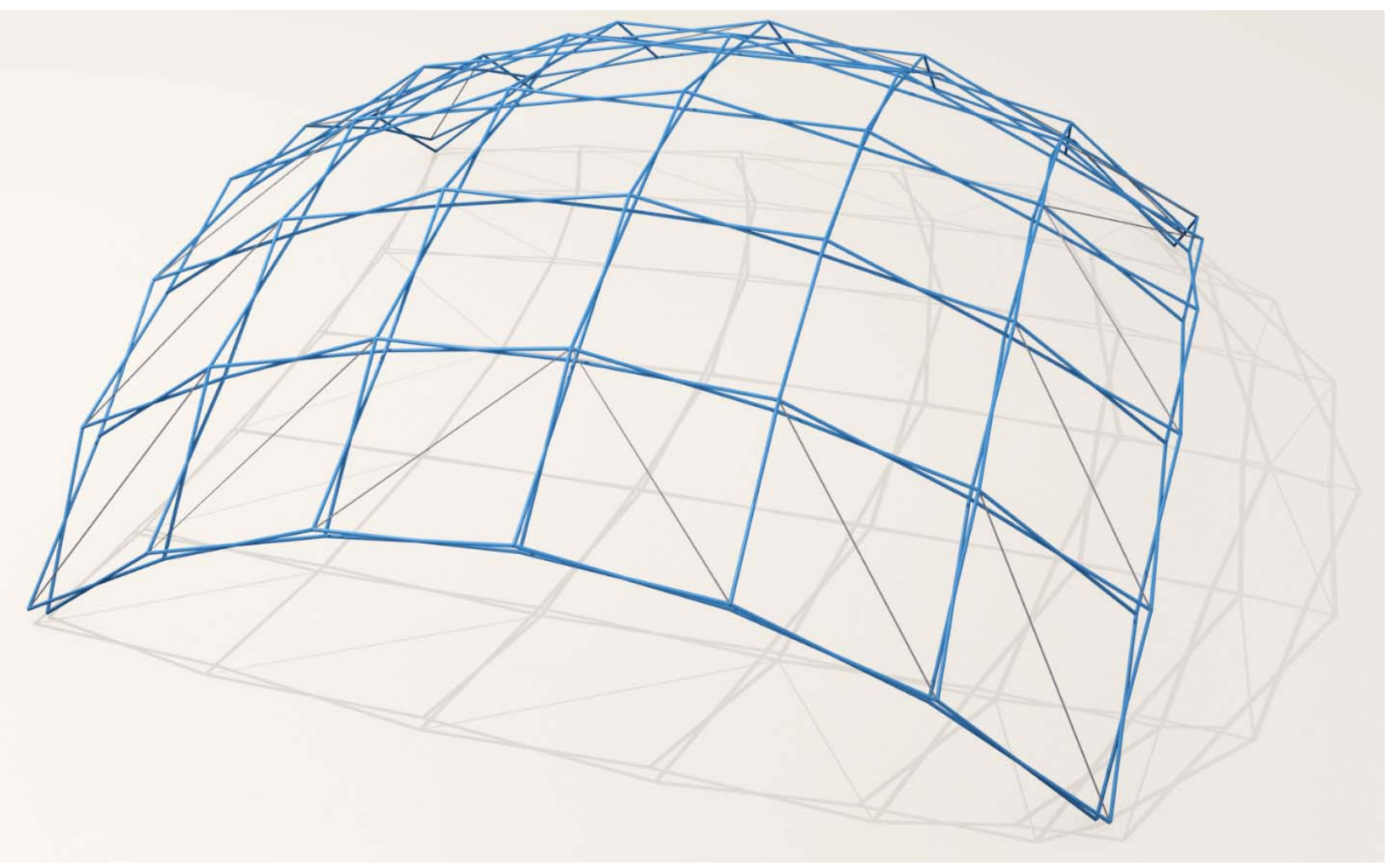

Figure 10.- Deployable sail dome.

In the case of cylindrical vaults there are two types of scissor-like elements: those which correspond to transversal arches and those which correspond to directrix longitudinal scissors. The need for folding 
means that the length of the longitudinal bars will be equal to the sum of both sections of transversal bars, so that the entire structure can be folded down into a compact package (figure 9).

With the $\alpha_{1}$ and $\beta$ values obtained, we are able to calculate the linkage diameter that is necessary for it to be reciprocal, by applying formula [1].

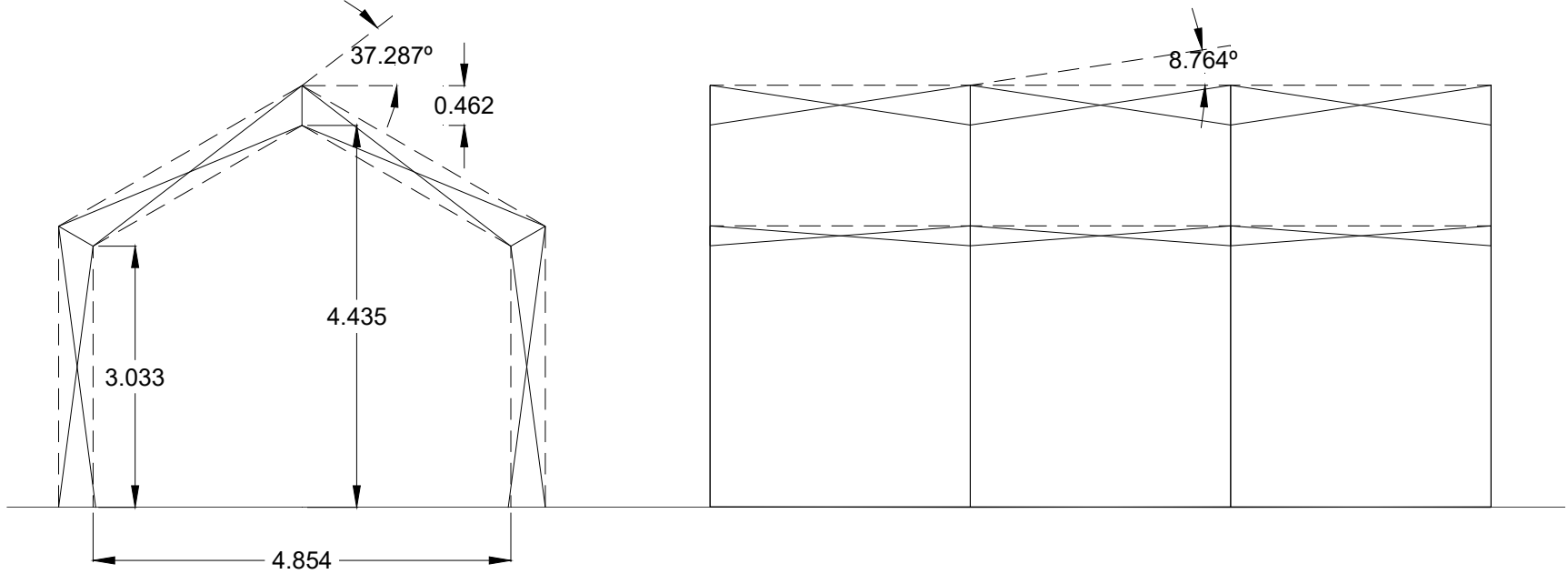

Figure 11.- Deployable structure with a gable roof.

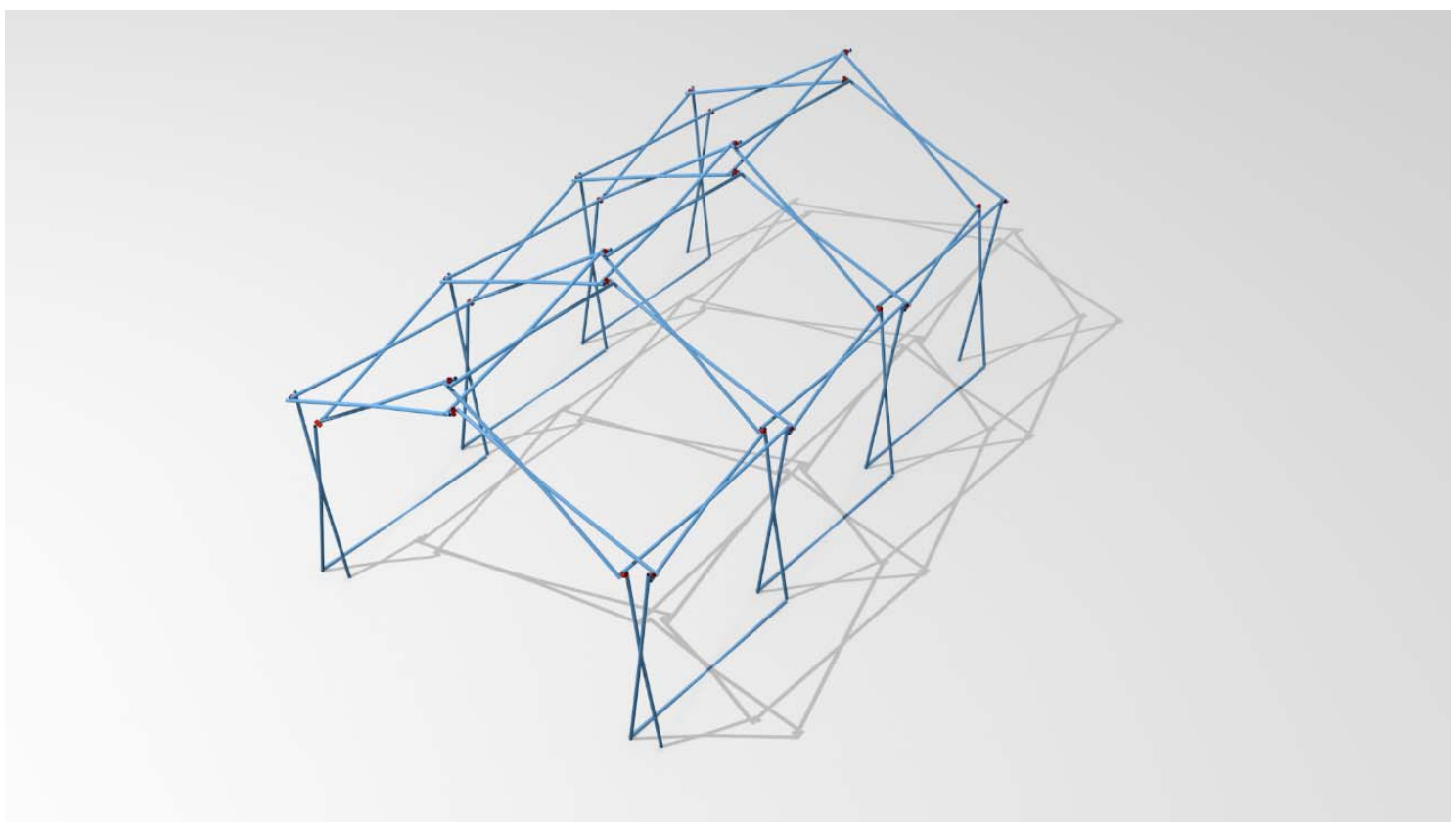

Figure 12.- Model of a deployable structure with a gable roof.

The use of reciprocal linkages in the upper layer makes it possible to develop interesting applications. Figures 11 and 12 show a cylindrical mesh with a polygonal directrix, the pattern of which was resolved recently [29]. This mesh may be opened to the point where the lower bars surpass the prolongation point between them, forming a construction that includes the walls and roof in a single deployable mesh. As the upper linkages are reciprocal, they are unable to move beyond this position and the mesh may only be folded in the correct direction. Although this would be a major drawback in deployable structures with articulated linkages, the proposed linkage easily resolves this.

With the indicated dimensions the angles that meet in the linkage are $\alpha=37.287^{\circ}$ in the transversal direction and $8.764^{\circ}$ longitudinally. This means that the ratio between linkage and bar width is $a / d=1.766$. In practice, a slightly smaller linkage was designed and the distance is adjusted using washers or bolts. 

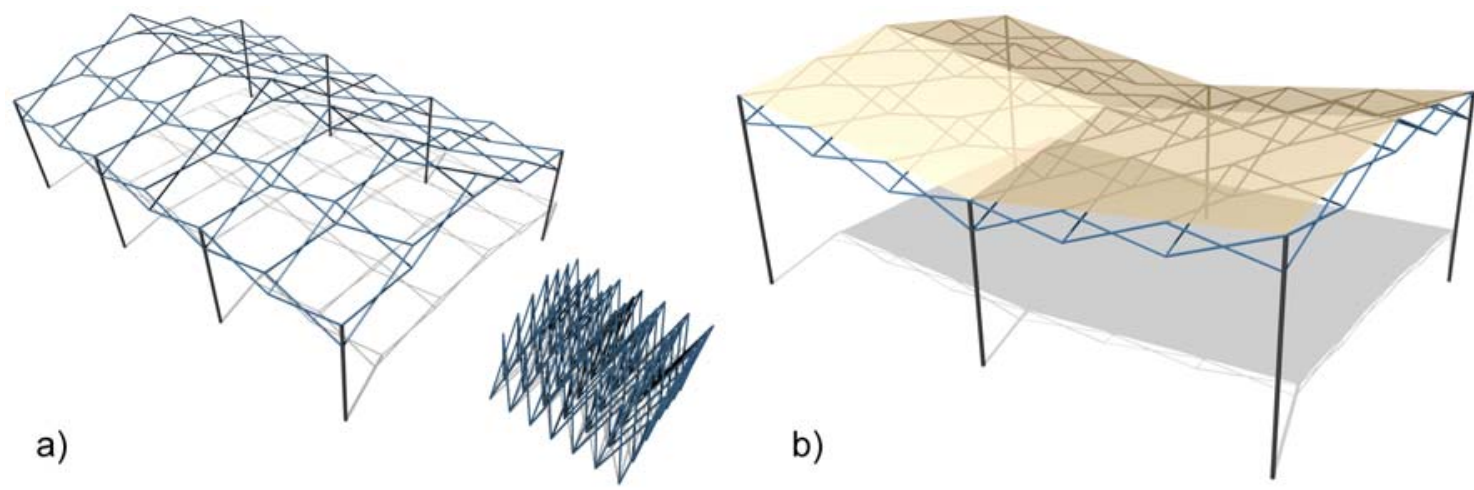

Figure 13.- Gable roof and hypar module meshes.

This system is especially simple in flat or cylindrical meshes formed by SLE with square modules. It is also applicable to many other more complex types of meshes, such as gable roof meshes (Figure 13a) and hyperbolic paraboloid meshes (Figure 13b). It can also be applied in other more complex designs, such as those proposed by Freire et al. [29]. In all cases, a careful study of the angles between bars is required, since they define the proportions between bar diameter and linkage size.

\section{Computational model.}

The most appropriate calculation model for structures of this type is Matrix Structural Analysis, which makes it possible to consider the effect of linkage eccentricity and the effect of non-linearity on structures of this type with a very high level of exactitude. This subject was completely resolved for articulated linkage structures in the 1990s [6, 28, 30,31].

In structures with reciprocal linkages it is necessary to modify their stiffness equation because the turning conditions at the ends of the bar have been modified. In effect, the end of the bar rests on the pin that joins it to the linkage and the adjacent bar. The resulting diagram is shown in figure 14, making it possible to easily calculate rigidity and the embedment factor using Mohr's theorems. For this we consider that we have a bar that rests on the pin and with reciprocal support on another one of the bars of the linkage. We consider that the flexion of the supporting bar can be ignored, given that it occurs very close to the linkage. We use e to refer to the distance from the pin to the point of support on the adjacent bar (equation [3]) and $L$ the length of the section of bar (Figure 14).

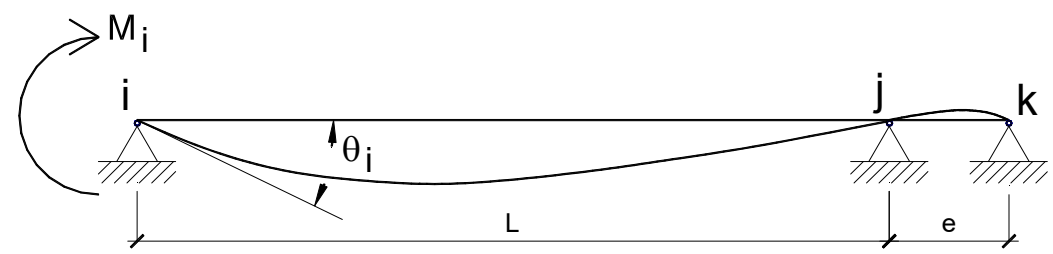

Figure 14.- Rigidity of the bar with reciprocal linkages.

Applying the conditions of turning, the moment transmitted to the end $\mathrm{j}$ is

$$
M_{j}=-\frac{M_{i} \cdot L}{2(L+e)}
$$

As the transmission factor in an embedded bar is 0.5 the degree of embedment will be

$$
g_{e}=\frac{L}{L+e}
$$

The flexural rigidity of the braced bar will be 


$$
R=\frac{M}{\theta}=\frac{3 E I}{L\left(1-\frac{L}{4(L+e)}\right)}
$$

The value of e (the distance between the axis of the pivot and the point where one bar rests on the next one), is defined by the geometrical conditions of the linkage and the bar, as is shown in equation [3]. Using this value it is possible to calculate rigidity and the degree of embedment of the bar. As an example, it is possible to mention one of the models that were made. It used a bar diameter of $25 \mathrm{~mm}$, a linkage diameter of $40 \mathrm{~mm}$, an opening angle of $24.62^{\circ}$ and a total bar length of $1500 \mathrm{~mm}$. Under these conditions $\mathrm{e}=35.75 \mathrm{~mm}$ and the degree of embedment will be $95.45 \%$. As can be seen, with the proportions that are normally used in deployable structures the reciprocally supported end may be considered to be almost completely embedded. In the calculations made, the degree of embedment for each bar has been considered.

The balance of the bar within space is defined by the forces at the three linkages, the bending moments due to the condition of reciprocity and by the position of the local axes with respect to the overall axes. The balance of the bar in space is defined by the forces and moments shown in figure 15. The forces correspond to the interactions between bars, while the moments correspond to the braced linkages. In the proposed linkage, the reciprocal joint affects the moments $M_{y}$, given that in direction $z$ there are none, although both cases are generally studied. The stiffness matrix in local coordinates may be defined by the displacements of the linkages and the degree of embedment of the ends, defined by the restrictions of the linkages (braced or shored linkages)

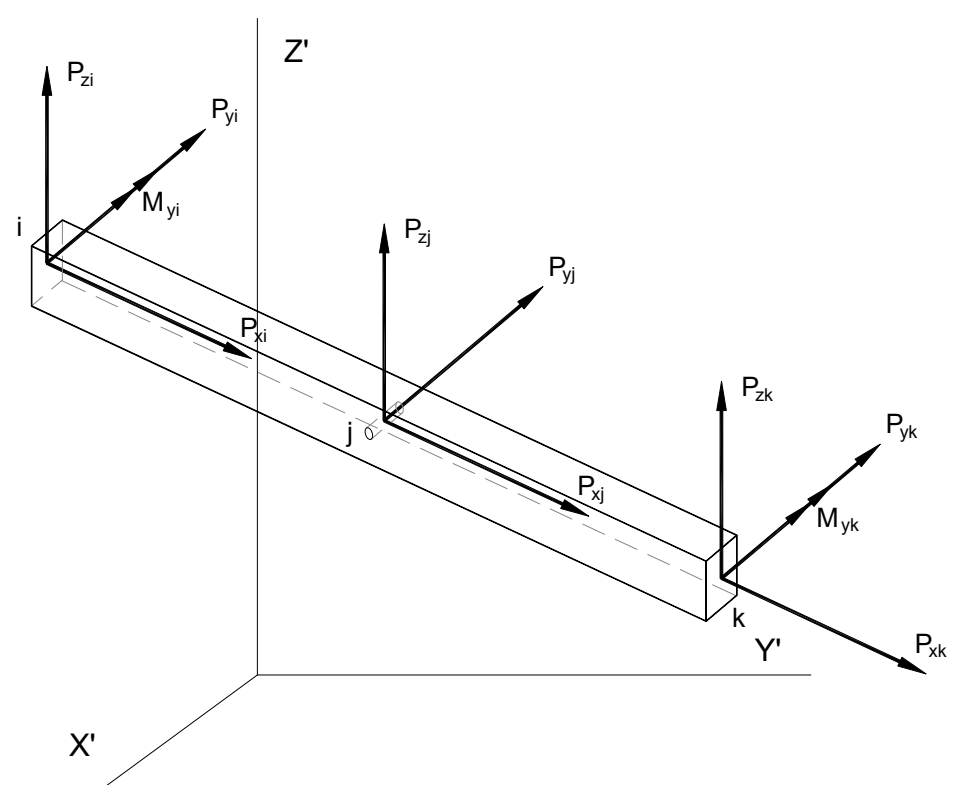

Figure 15.- Balance of a bar with three articulations in space, with L-shaped linkages at its ends. 

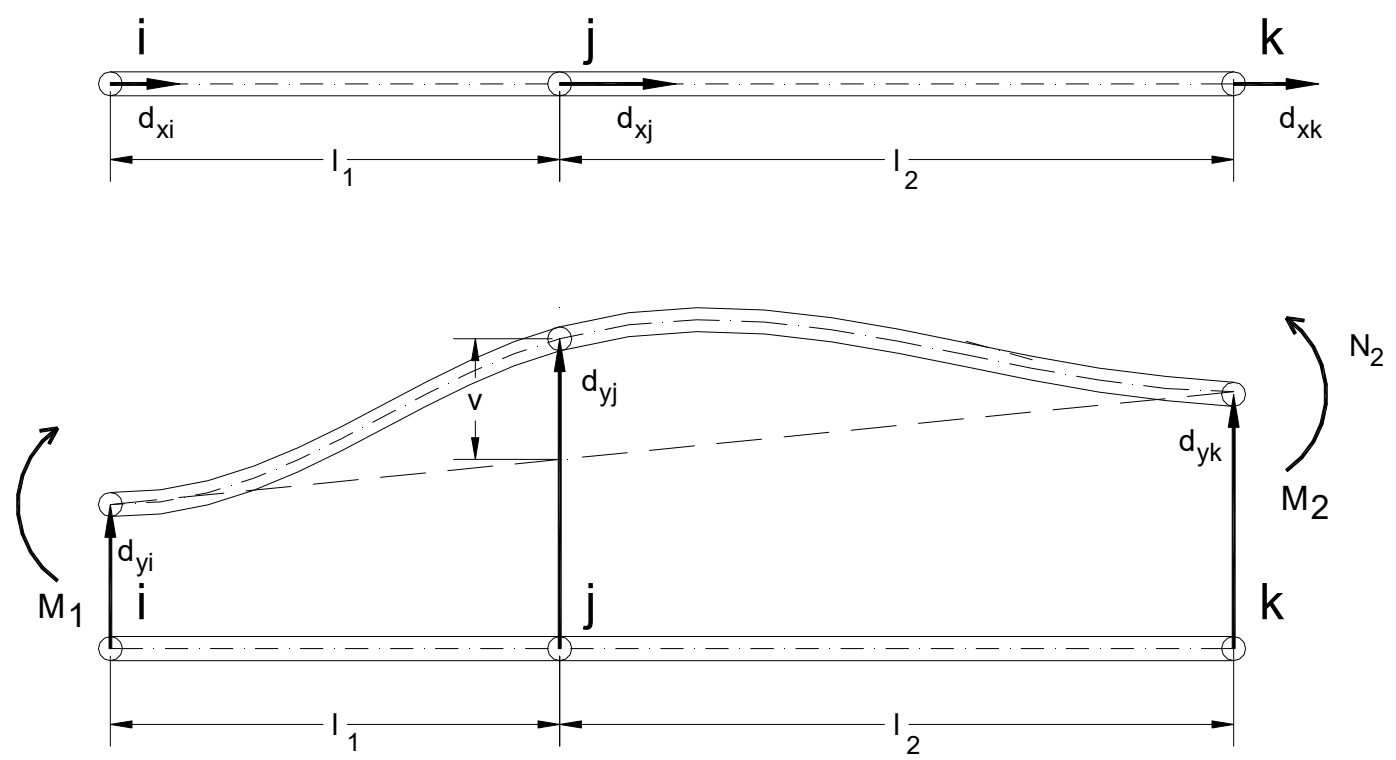

Figure 16.- Displacements of the linkages of a bar in a reciprocal deployable structure.

To establish the stiffness equation it is necessary to consider that the bar is subjected to axial forces that cause both sections of the bar to lengthen or shorten, although it is also subjected to transversal forces that cause it to bend. The lengthening of the two sections of the bar can be formulated as

$$
\left.\begin{array}{lll}
u_{1}=d_{x j}-d_{x i}=-\frac{l_{1}}{E \cdot A} \cdot P_{x i} & ; & P_{x i}=\frac{E \cdot A}{l_{1}} \cdot\left(d_{x i}-d_{x j}\right) \\
u_{2}=d_{x k}-d_{x j}=\frac{I_{2}}{E \cdot A} \cdot P_{x k} & ; & P_{x k}=\frac{E \cdot A}{I_{2}} \cdot\left(d_{x k}-d_{x j}\right)
\end{array}\right\} \quad P_{x j}=-P_{x i}-P_{x k}
$$

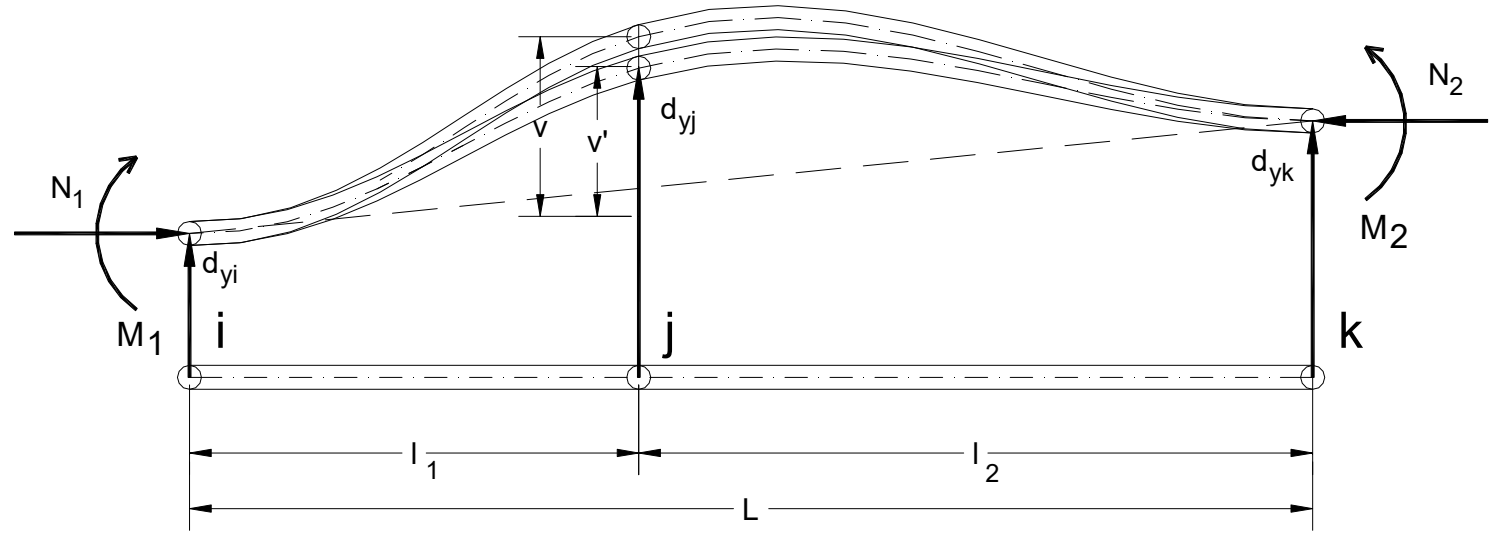

Figure 17.- Transversal deformation cause by axial forces on the bar with reciprocal linkages.

To calculate transversal deformation the bar is considered to be supported at its ends, and transversal force in the central linkage causes bending according to its axis, affecting displacements in direction $z$. The conditions for effective reciprocal support do not exist in the other direction. The deflection values at the central linkage would be 


$$
\begin{aligned}
& \mathrm{k}_{\mathrm{M}}=1-\frac{\mathrm{g}_{1} \cdot \mathrm{I}_{2}}{\mathrm{I}_{1}} \cdot\left(1-\frac{\mathrm{I}_{2}^{2}}{\mathrm{~L}^{2}}\right)-\frac{\mathrm{g}_{2} \cdot \mathrm{I}_{1}}{\mathrm{I}_{2}} \cdot\left(1-\frac{\mathrm{I}_{1}^{2}}{\mathrm{~L}^{2}}\right) \\
& \mathrm{V}^{\prime}=\frac{1}{\mathrm{E} \cdot \mathrm{I}_{\mathrm{y}}} \cdot \frac{\mathrm{P}_{\mathrm{yj}} \cdot \mathrm{I}_{1}^{2} \cdot \mathrm{I}_{2}^{2}}{3 \cdot \mathrm{L}} \Rightarrow \mathrm{P}_{\mathrm{yj}}=\frac{3 \cdot \mathrm{E} \cdot \mathrm{I}_{\mathrm{y}} \cdot \mathrm{L}}{\mathrm{I}_{1}^{2} \cdot \mathrm{I}_{2}^{2}} \cdot \mathrm{V}^{\prime} \\
& \mathrm{w}^{\prime}=\frac{1}{\mathrm{E} \cdot \mathrm{I}_{\mathrm{z}}} \cdot \frac{\mathrm{P}_{\mathrm{zj}} \cdot \mathrm{I}_{1}^{2} \cdot \mathrm{I}_{2}^{2}}{3 \cdot \mathrm{L}} \cdot \mathrm{k}_{\mathrm{M}} \Rightarrow \mathrm{P}_{\mathrm{zj}}=\frac{3 \cdot \mathrm{E} \cdot \mathrm{I}_{\mathrm{z}} \cdot \mathrm{L}}{\mathrm{I}_{1}^{2} \cdot \mathrm{I}_{2}^{2} \cdot \mathrm{k}_{\mathrm{M}}} \cdot \mathrm{w}^{\prime}
\end{aligned}
$$

These equations correctly represent the displacements caused by transversal forces, under the hypothesis of elastic lineal behaviour. The effect of axial forces on the deformed bar causes bending moments that increase the deformation of the same, as may be seen in figure 17. These deformations are due to non-lineal behaviour that has to be considered. To consider these effects we will introduce two stability functions, $\phi_{\mathrm{y}}$ and $\phi_{\mathrm{z}}$, that correspond to the bending along these axes and which are the quotient between the deflection $v$, which is what actually occurs, and deflection $v$ ' which would be produced if the axial forces did not affect deformation [26]. Of course, if the aim is only to make a lineal calculation, then $\phi_{y}$ and $\phi_{z}$ will be made equal to 1 . When the bar is compressed the stability functions will be greater than 1 , and if the bar is under traction they will be lower than 1 .

The resulting equations are

$$
\begin{aligned}
& v=\phi_{y} \cdot v^{\prime} \quad ; \quad v=\frac{\phi_{y}}{E \cdot I_{y}} \cdot \frac{P_{y j} \cdot I_{1}{ }^{2} \cdot I_{2}^{2}}{3 \cdot L} \quad \Rightarrow \quad P_{y j}=\frac{3 \cdot E \cdot I_{y} \cdot L}{\phi_{y} \cdot I_{1}^{2} \cdot I_{2}{ }^{2}} \cdot v \\
& w=\phi_{z} \cdot w^{\prime} \quad ; \quad w=\frac{\phi_{z}}{E \cdot I_{z}} \cdot \frac{P_{z j} \cdot I_{1}^{2} \cdot I_{2}^{2}}{3 \cdot L} \cdot k_{M} \quad \Rightarrow \quad P_{z j}=\frac{3 \cdot E \cdot I_{z} \cdot L}{\phi_{z} \cdot I_{1}^{2} \cdot I_{2}{ }^{2} \cdot k_{M}} \cdot w
\end{aligned}
$$

Expressing deflections as a function of the displacements of the linkages

$$
\begin{aligned}
& v=d_{y j}-\frac{d_{y i}+d_{y k}}{2} ; \quad w=d_{z j}-\frac{d_{z i}+d_{z k}}{2} \\
& P_{y j}=\frac{3 \cdot E \cdot I_{y} \cdot L}{\phi_{y} \cdot I_{1}^{2} \cdot I_{2}^{2}} \cdot\left(d_{y j}-\frac{d_{y i}+d_{y k}}{2}\right)=-\frac{3 \cdot E \cdot I_{y} \cdot L}{2 \phi_{y} \cdot I_{1}^{2} \cdot I_{2}^{2}} \cdot d_{y i}+\frac{3 \cdot E \cdot I_{y} \cdot L}{\phi_{y} \cdot I_{1}^{2} \cdot I_{2}^{2}} \cdot d_{y j}-\frac{3 \cdot E \cdot I_{y} \cdot L}{2 \phi_{y} \cdot I_{1}^{2} \cdot I_{2}^{2}} \cdot d_{y k} \\
& P_{z j}=\frac{3 \cdot E \cdot I_{z} \cdot L}{\phi_{z} \cdot l_{1}^{2} \cdot I_{2}^{2} \cdot k_{M}} \cdot\left(d_{z j}-\frac{d_{z i}+d_{z k}}{2}\right)=-\frac{3 \cdot E \cdot I_{z} \cdot L}{\phi_{z} \cdot l_{1}^{2} \cdot I_{2}^{2} \cdot k_{M}} \cdot d_{z i}+\frac{3 \cdot E \cdot I_{z} \cdot L}{\phi_{z} \cdot l_{1}^{2} \cdot I_{2}^{2} \cdot k_{M}} \cdot d_{z j}-\frac{3 \cdot E \cdot I_{z} \cdot L}{2 \phi_{z} \cdot l_{1}^{2} \cdot I_{2}^{2} \cdot k_{M}} \cdot d_{z k}
\end{aligned}
$$

And the forces at the ends of the bars will be the reactions that correspond to these transversal forces.

The stiffness equation of the bar in local coordinates is $\tilde{P}=\tilde{K} \cdot \tilde{d}$ where 


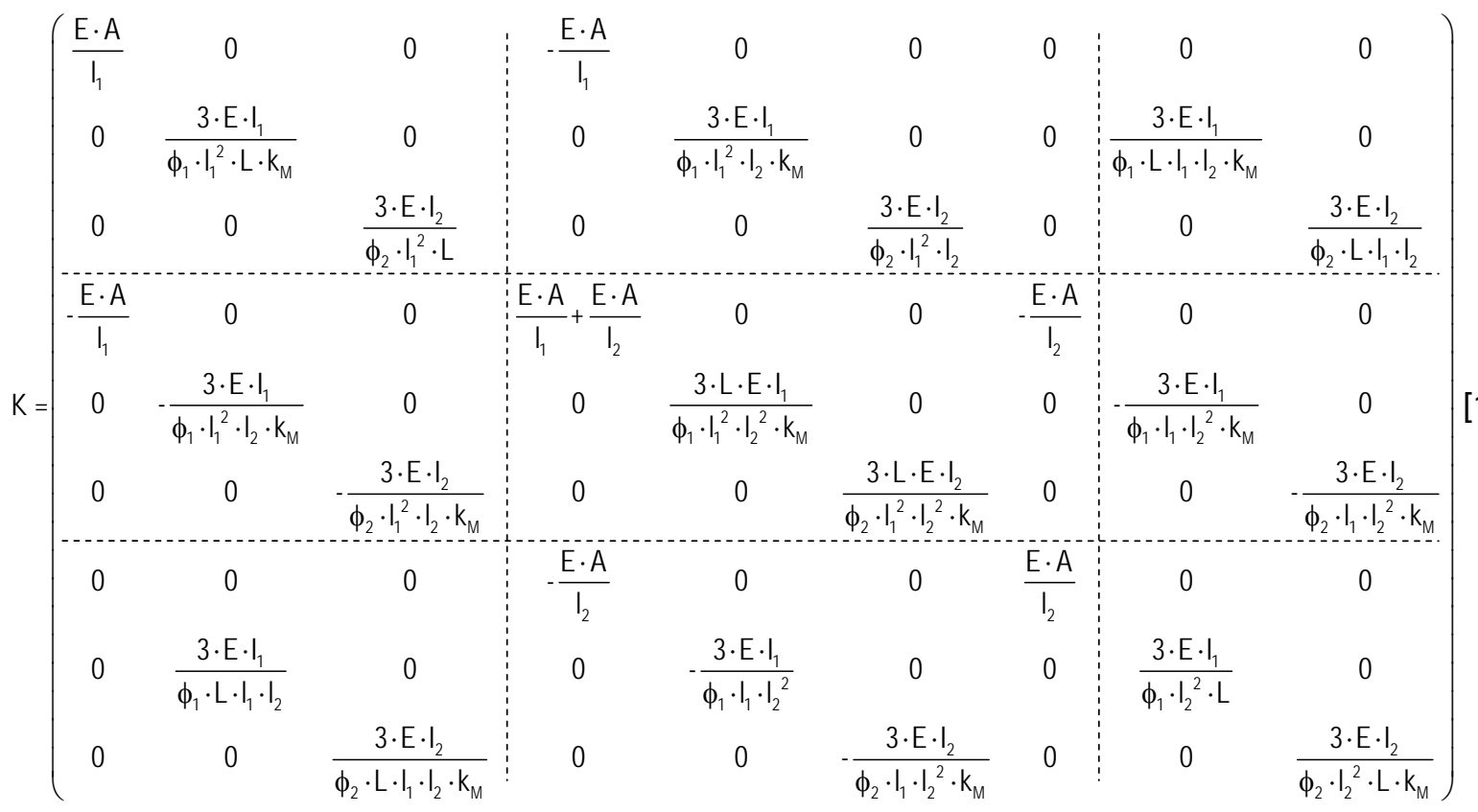

The compatibility matrix $\tilde{\mathrm{A}}$ is simply the rotation matrix that corresponds to the change of axes. Applying the balance equation gives the system of equations to be solved to calculate the forces and displacements of the structure.

$$
\tilde{P}^{\prime}=\left(\tilde{A}^{-1} \cdot \tilde{K} \cdot \tilde{A}\right) \cdot \tilde{d}^{\prime}
$$

These parameters are entered into the Despleg 19.1 calculation program, which permits the matrix calculation of structures of bars applying these conditions. To validate these calculations we made the models that are analysed in section 4.3.

An important advantage of linkages of this type is that they clearly reduce bending moments on the bar. Figure 18a shows the bending moments acting on a bar with articulated ends, and Figure 18b shows the bending moments acting on a bar with reciprocal linkages. The greatest moments arise in the vertical direction $z$, which is the direction in which the reciprocal linkages work. The $M_{z}$ moments do not vary, although in the vertical direction the degree of embedment of the end reduces the moments by almost half. These bending moments are the most unfavourable forces acting on deployable structures.

Z

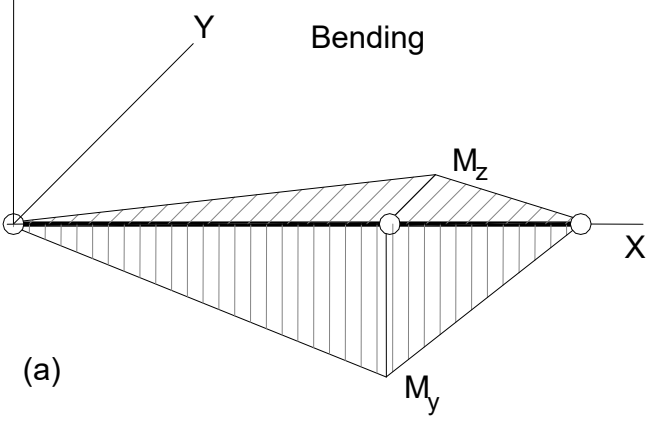

Z

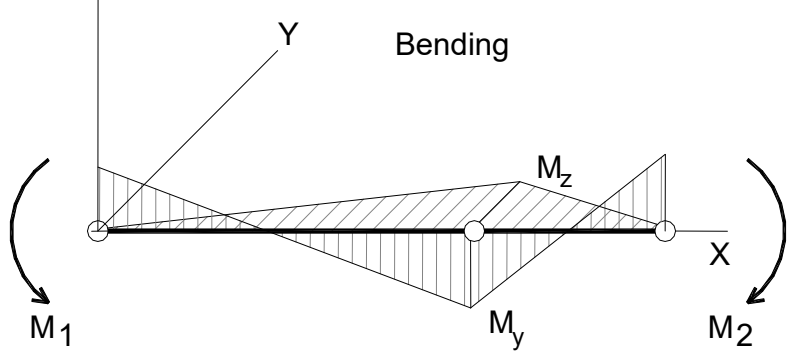

(b)

Figure 18.- Bending moment diagrams for articulated and reciprocal linkages. 


\section{Materials and methods.}

\subsection{Test elements}

A series of tests with flat deployable structures were performed to check the efficacy of reciprocal linkages. Although other types of deployable structure were constructed and tested during the study, a flat mesh has several advantages as a test element. Firstly, this type of mesh is highly deformable, so that the advantages of using reciprocal linkages stand out strongly. Secondly, although this type of structure is a mechanism when articulated linkages are used, the use of reciprocal linkages makes it possible to design meshes that are braced in their final position, without the need for additional bars or external constraints, which are hard to achieve in practice.

Flat meshes have hardly been used, in spite of their simplicity and low cost. They are so deformable when bars articulated at their ends are used that they are ineffective for practical use. For this reason they have hardly ever been constructed or proposed for use. Only Pérez Piñero used them in a single instance, using bracing bars to create rigidity [3]. There is also one proposal for a sports pavilion roof with stiffening bars and internal articulation that is locked after deployment, although this was never built [10].

The tests performed with reciprocal linkages and sliding and fixed ends proved their efficacy. These results are contained in a recent paper that is currently in press. The theoretical results also show good behaviour of the mesh, with an appreciable reduction in linkage displacements. Experimental confirmation was therefore required, and a series of tests were carried out for this purpose.

Two models of the same kind of mesh were built to this end, one with reciprocal support linkages and the other with simply articulated linkages. The pattern used is shown in figure 19, indicating the positions of the linkages and bars that correspond to the results of calculations and trials.

These modules were tested on a loading bed to measure displacements. Loading-unloading cycles were performed and the results were compared to the theoretical ones, in order to validate the calculation model.

\subsection{Materials}

The test model bars are T5 6060-type $\varnothing 16 \mathrm{~mm}$ and $1.9 \mathrm{~mm}$ thick aluminium tubes (aluminium magnesium - silicon) (figure 20). They have a specific weight of $2700 \mathrm{kN} / \mathrm{m}^{3}$, a modulus of elasticity of $69500 \mathrm{~N} / \mathrm{mm}^{2}$, an elastic limit of $185 \mathrm{~N} / \mathrm{mm}^{2}$ and a failure load of $220 \mathrm{~N} / \mathrm{mm}^{2}$. $\varnothing 13 \mathrm{~mm}$ and $1.5 \mathrm{~mm}$ thick aluminium tubes made of the same material were used for the bracing bars that were placed at the corners of the mesh in some tests.

The linkages are composed of sections of hollow aluminium tube (SHS) of the same quality. They are 20 $\mathrm{mm}$ across, $1 \mathrm{~mm}$ thick and $20 \mathrm{~mm}$ tall. The pivots are composed of $4 \mathrm{~mm}$ threaded steel bars that are welded to the central part. The bolts and threaded bars are in 5.6 quality steel according to ISO 898-1. They have a modulus of elasticity of $200000 \mathrm{~N} / \mathrm{mm}^{2}$, an elastic limit of $300 \mathrm{~N} / \mathrm{mm}^{2}$ and a failure load of 500 $\mathrm{N} / \mathrm{mm}^{2}$ with a $20 \%$ elongation.

\subsection{Fabrication of the elements}

1:4 scale models were built to check the validity of the proposed linkages, using the bars and linkages described. These structures are especially simple, given that they may be made of bars which are all of the same lengths. Additionally the proportion between the diameter of the linkage and that of the bar D/d is always the same, so that all of the linkages are uniform. For this reason, they are especially simple to manufacture and assemble, depending on the foreseen use.

Both models tested are composed of four square modules composed of SLE. The distance between the axes of turning is $470 \mathrm{~mm}$. In the reciprocal linkage model the bar is elongated by $30 \mathrm{~mm}$ from the axis of the end pivot, so that the total bar length is $1000 \mathrm{~mm}$. In the articulated linkage model the bar is elongated by $10 \mathrm{~mm}$, so that its total length amounts to $960 \mathrm{~mm}$. The side of the mesh measures $447 \mathrm{~mm}$ and the angle of the bars is $28.71^{\circ}$. The result of this is that the proportion between the linkage and bar is 1.3094 . 
The necessary linkage diameter is $20.95 \mathrm{~mm}$. The linkage was adjusted to the exact diameter using two $0.5 \mathrm{~mm}$ washers, ensuring the reciprocal support of all the bars (Figure 20). Two models of the meshes with reciprocal linkages were tested, one with bracing bars at the corners and the other without them. The articulated linkage mesh was only tested with the bracing bars, given that without these it is a mechanism.
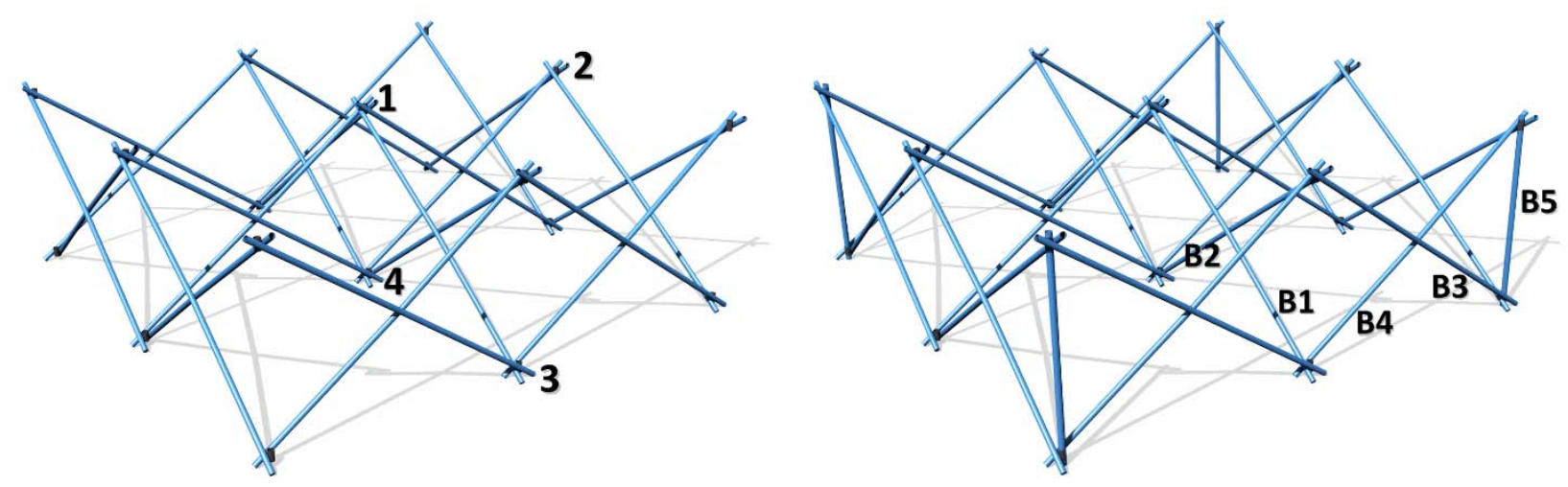

Figure 19.- Models of bars without bracing bars (left) and with bracing bars (right), showing the position of the sensors and the bars checked.

The models were subjected to tests in the A Coruña ETS Arquitectura structures laboratory using a test bench made in the department. Five $10 \mathrm{kgf}(98.1 \mathrm{~N})$ loads were applied to the linkages of the upper layer, located in the centre of the mesh and at the centres of the side faces. Displacements were measured using Schreiber Sm407.100.2.T inductive displacement sensors with a linearity of $<0.25 \%$ and deviation of $<0.01 \% /{ }^{\circ} \mathrm{C}$. Data gathering was completed using Y103 digital extensometers with a precision of \pm 0.1 $\mathrm{mm}$. Displacements were measured at the centre of the mesh and at one of its edges, in the upper and lower linkages.

The models were supported by four pieces of wood with polypropylene plates that allowed the supports to slide. Friction was minimum, so that the sole effective constraint was vertical displacement. This is the least favourable situation for the mesh. Under real conditions horizontal movement would be constrained, so that vertical displacements would be less pronounced. As efficacy in terms of vertical displacement was being tested, it was considered appropriate to design the model for an especially unfavourable situation.

The models were loaded with five calibrated $10 \mathrm{kgf}$, pieces. This is equivalent to a load of approximately $0.20 \mathrm{kN} / \mathrm{m}^{2}$ on the constructed modules. Although the loads are similar to those on a real structure with these characteristics, the aim of the test was to validate the calculation model, so that any loads could have been used. It is only necessary that the same loads be applied in the calculation model, so that the results can be compared.

\subsection{Test organisation}

Model 1 was tested first to check the reciprocal linkage mesh without bracing bars at the corners. This test had the aim of checking the validity of a mesh model that is only viable with reciprocal linkages. The same structure with articulated linkages is a mechanism and therefore unable to resist external loads.

Both meshes were then tested with bracing bars at their corners, joining the upper and lower linkages (models 2 and 3 ). This meant that the articulated linkage mesh ceased to be a mechanism and its displacements were comparable to those of the same mesh, but with reciprocal linkages.

In all of the tests a first step of loading was applied to adjust the linkages. This is an extremely important aspect for deployable structures. As they are mobile, the linkages and joints need to have a certain tolerance. When the structure is placed under load it adjusts and undergoes a certain initial displacement. After the load corresponding to this first step is removed, the structure largely remains in its adjusted position, although it returns to its original state to a very limited extent. When the next loading step is applied the structure deforms according to the load. This is essential if the aim is to validate calculation methodology by experimental results. Adjustment displacements would distort the results measured and prevent any effective comparison. 


\section{Results.}

\subsection{Theoretical model}

The models tested were checked using the Despleg19.1 program, which uses the matrix structural analysis. In the case of the mesh with reciprocal linkages, the program assigned a degree of embedment to the linkages at the ends of the bar which was entered as a datum. The program assumed a sliding joint for the interior linkages of the bars. It considered the displacements of both points joined to the linkage to be equal, although the bars may turn freely within the plane of the scissor. The calculation for the articulated linkages mesh considered the bars to lack rigidity at their ends, so that the calculation method described in reference [29] was used for them.

\begin{tabular}{cccccccccc} 
Angle $\alpha$ & Angle $\beta$ & a/d & $d$ (bar) & a (Link.) & $d\left(A_{1}, P_{1}\right)$ & $d\left(A_{2}, P_{2}\right)$ & $L$ & $G_{e 1}$ & $G_{e 2}$ \\
\hline 28.71 & 28.71 & 1.309432 & 16 & 20.95 & 13.17 & 13.17 & 465.00 & $97.25 \%$ & $97.25 \%$
\end{tabular}

In the reciprocal linkages models tested, the degree of embedment amounts to $97.25 \%$. In the linkages where four bars join this degree of embedment is applied to all of the bars. In the model that was tested this only occurs in the central upper and lower linkages. In the linkages at the sides and corner it may only be applied to the bars which rest reciprocally on others. The ends of the bars that are not supported must be considered to have $0 \%$ degree of embedment. In the calculation of the mesh with articulated linkages, the degree of embedment is always $0 \%$.

Constraints are applied so that the model may be considered to be simply supported, and vertical displacement is only prevented at the four corners. The loads are those of the actual model, and the results refer to the points where the sensors were applied.

Table 1.- Results of the theoretical calculations

Reciprocal linkages

\begin{tabular}{cccc|ccccc}
\hline \multicolumn{6}{c|}{ Displacements in points $(\mathrm{mm})$} & \multicolumn{5}{c}{ Stress in bars (MPa) } \\
\hline 1 & 2 & 3 & 4 & B1 & B2 & B3 & B4 & B5 \\
19.33 & 11.84 & 9.42 & 17.86 & 34.73 & 7.04 & 74.29 & 12.96 & 23.80 \\
\multicolumn{8}{c}{ Articulated linkages } \\
\hline \multicolumn{7}{c}{ Displacements in points $(\mathrm{mm})$} & \multicolumn{7}{c}{ Stress (MPa) } \\
\hline 1 & 2 & 3 & 4 & B1 & B2 & B3 & B4 & B5 \\
44.47 & 28.91 & 2.30 & 0.93 & 45.24 & 11.04 & 90.70 & 16.44 & 24.20 \\
\hline $130.06 \%$ & $144.17 \%$ & $-75.58 \%$ & $-94.79 \%$ & $30.26 \%$ & $56.82 \%$ & $22.09 \%$ & $26.85 \%$ & $1.68 \%$
\end{tabular}

The final line shows the increases between the values calculated for the mesh with reciprocal linkages and those for the mesh with articulated linkages.

\subsection{Experimental results}

The tests were performed with the load arranged on the linkages of the upper layer and with the displacement sensors at the points shown in figure 19. The load was gradually applied over approx. 5 seconds. The load was maintained during sufficient time for displacements to stabilise, from 10 to 15 seconds, and then the load was gradually removed over 5 seconds. Three tests were performed for each one of the cases.

\subsubsection{Flat meshes with reciprocal linkages without bracing bars at the corners}




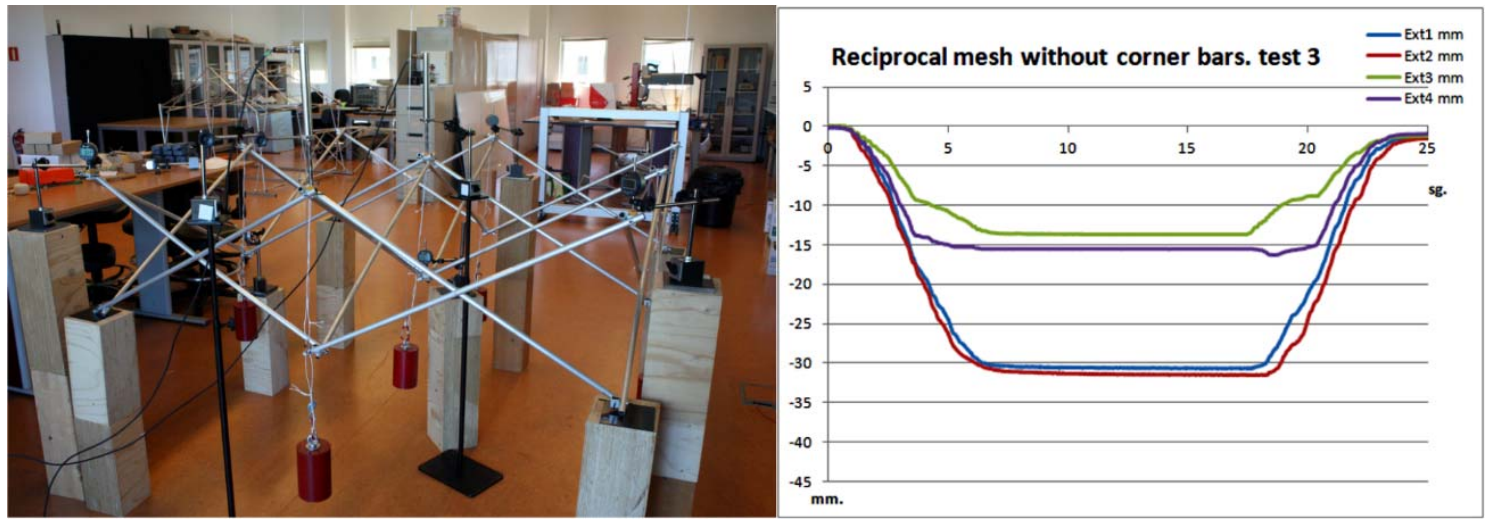

Figure 20.- Test displacements in meshes with reciprocal linkages without corner bars.

5.2.2 Flat meshes with reciprocal linkages with bracing bars at the corners

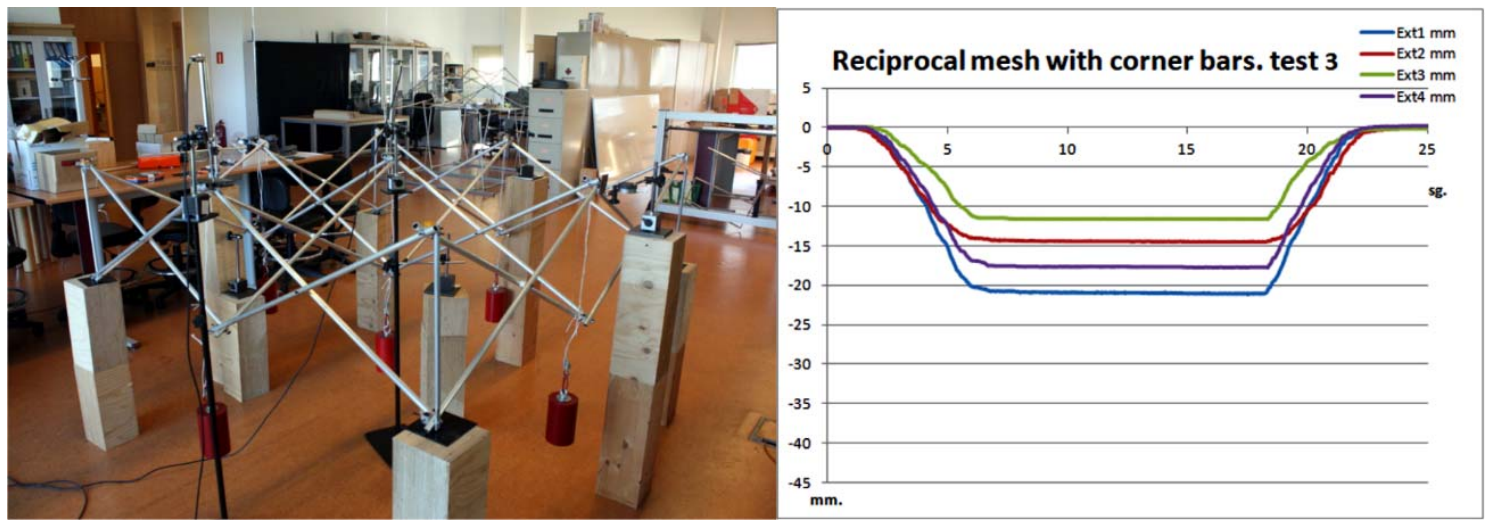

Figure 21.- Test displacements in meshes with reciprocal linkages and corner bars

5.2.3 Flat meshes with articulated linkages with bracing bars at the corners

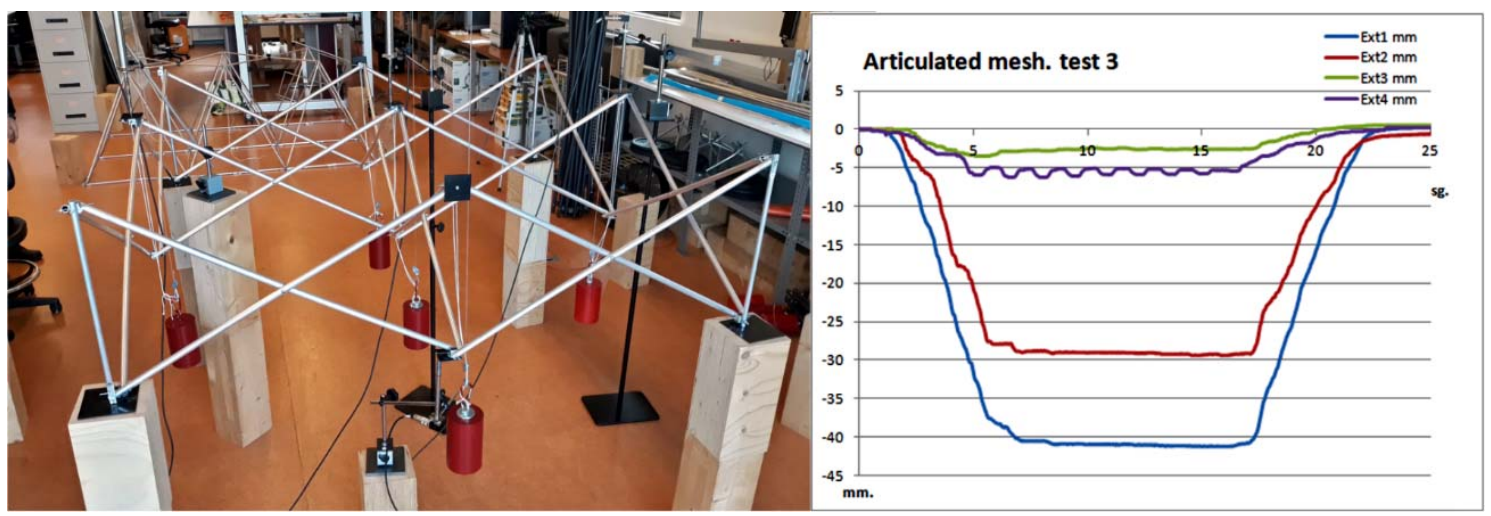

Figure 22.- Test displacements in meshes with articulated linkages and corner bars.

The following table shows a summary of the test results 
Table 2.- Displacements measured.

\begin{tabular}{|c|c|c|c|c|c|c|c|c|c|c|c|c|}
\hline \multirow[b]{3}{*}{ Points } & \multicolumn{4}{|c|}{$\begin{array}{l}\text { With additional bars } \\
\text { Reciprocal linkages }\end{array}$} & \multicolumn{4}{|c|}{$\begin{array}{l}\text { With additional bars } \\
\text { Articulated linkages }\end{array}$} & \multicolumn{4}{|c|}{$\begin{array}{l}\text { Without additional bars } \\
\text { Reciprocal linkages }\end{array}$} \\
\hline & \multicolumn{4}{|c|}{ Displacements $\mathrm{mm}$} & \multicolumn{4}{|c|}{ Displacements mm } & \multicolumn{4}{|c|}{ Displacements $\mathrm{mm}$} \\
\hline & 1 & 2 & 3 & 4 & 1 & 2 & 3 & 4 & 1 & 2 & 3 & 4 \\
\hline Test 1 & 20.87 & 14.50 & 11.34 & 17.73 & 41.75 & 28.56 & 2.73 & 4.97 & 30.83 & 31.42 & 13.48 & 15.47 \\
\hline Test 2 & 21.02 & 14.79 & 11.60 & 17.76 & 41.16 & 27.91 & 2.99 & 5.47 & 30.40 & 30.69 & 13.75 & 15.94 \\
\hline Test 3 & 20.95 & 14.50 & 11.51 & 17.66 & 41.24 & 29.22 & 2.58 & 5.67 & 30.62 & 31.35 & 13.75 & 15.60 \\
\hline
\end{tabular}

\section{Discussion.}

To test the effectiveness of the reciprocal linkages it is necessary to compare the results of the articulated linkage mesh with those of the reciprocal linkage mesh. Firstly it should be noted that the experimental results coincide to a high degree. As may be seen in Table 3, the maximum deviation in the meshes with reciprocal linkages is $1.17 \%$, while in the articulated linkage mesh it was $7.60 \%$. The results show a better fit in linkages 1 and 2 . These are the linkages in which the four bars that concur in it are reciprocally supported. Furthermore, the acting load causes the bars to come into contact. These are the linkages whose real conditions are closer to the theoretical ones, so their results are especially representative.

Table 3.- Comparison of the experimental results.

\begin{tabular}{lcccc|cccc} 
& \multicolumn{3}{c|}{ Reciprocal linkages } & \multicolumn{4}{c}{ Articulated linkages } \\
\cline { 2 - 9 } & \multicolumn{3}{c}{ Displacements mm } & \multicolumn{4}{c}{ Displacements mm } \\
Points & 1 & 2 & 3 & 4 & 1 & 2 & 3 & 4 \\
Test 1 & 20.87 & 14.50 & 11.34 & 17.73 & 41.75 & 28.56 & 2.73 & 4.97 \\
Test 2 & 21.02 & 14.79 & 11.60 & 17.76 & 41.16 & 27.91 & 2.99 & 5.47 \\
Test 3 & 20.95 & 14.50 & 11.51 & 17.66 & 41.24 & 29.22 & 2.58 & 5.67 \\
Standard deviation & 0.07 & 0.17 & 0.13 & 0.05 & 0.32 & 0.66 & 0.21 & 0.36 \\
& $0.35 \%$ & $1.16 \%$ & $1.17 \%$ & $0.28 \%$ & $0.77 \%$ & $2.31 \%$ & $7.60 \%$ & $6.76 \%$
\end{tabular}

When the experimental results of both types of mesh are compared, it may be seen that displacements in the upper layer of the articulated linkage mesh are greater by up to $97.55 \%$ than the displacements in the reciprocal linkage mesh (Table 4). On the other hand, displacements in the lower layer linkages are smaller in the articulated linkages. This is because the set of SLE forms pantograph-shaped boxes in which greater displacement of the upper linkages leads to less displacement in the lower ones. This does not confer any advantage on the articulated linkage mesh. On the contrary, the reciprocal linkage mesh undergoes smaller maximum displacements with less distortion between them.

Table 4.- Comparison of the averaged displacements.

\begin{tabular}{lcccc|cccc} 
& \multicolumn{3}{c|}{ Reciprocal linkages } & \multicolumn{4}{c}{ Articulated linkages } \\
\cline { 2 - 8 } & \multicolumn{3}{c|}{ Displacements mm } & \multicolumn{4}{c}{ Displacements mm } \\
Points & 1 & 2 & 3 & 4 & 1 & 2 & 3 & 4 \\
Average value & 20.95 & 14.60 & 11.48 & 17.72 & 41.38 & 28.56 & 2.77 & 5.37 \\
Increase & & & & & $97.55 \%$ & $95.65 \%$ & $-75.92 \%$ & $-69.70 \%$
\end{tabular}

On the other hand, the reciprocal linkage system makes it possible to construct meshes that would be mechanisms if they had used articulated linkages. This is the case for a deployable mesh without bracing bars at the corners, on which it simply rests. Naturally the displacements are greater than they would be with bars at the corners. This is a normal situation. The bars that join the upper and lower layers in deployable structures are one of the most effective means of stabilising the mesh after deployment. They also considerably reduce displacements and forces within the whole structure [11]. Displacements of the 
reciprocal mesh without bars at the corners increase by $47.16 \%$ in comparison with the same structure with the indicarted bars. Even with the corner bracing bars the corresponding percentage is $73.84 \%$ for the structure with articulated linkages.

The experimental results show deviations of less than $1.5 \%$ with the theoretical predictions in the case of meshes with reciprocal linkages and greater in meshes with articulated linkages. It is necessary to take into account the fact that deployable structures have a certain degree of tolerance to permit folding and unfolding movements. In the models used the pin diameter is $4 \mathrm{~mm}$, while the diameter of the drilled hole in the bar is $4.2 \mathrm{~mm}$. This gives a tolerance of $0.2 \mathrm{~mm}$ that is introduced as an initial displacement of the bars. In this case the displacements of the linkages in the upper layer, which is where the loads are applied, fit the predictions very accurately. On the contrary, the displacements of the linkages in the lower layer vary more widely from the predictions, which we believe is due to the fact that they are not under load.

\section{Conclusions.}

The new proposed system of deployable structures with reciprocal linkages is clearly more effective than the traditional system of articulated linkages. The meshes are self-stabilising in their final position without needing bracing bars for stiffening. Their reciprocity also permits a high degree of embedment at the bar ends, improving their strength to resist bending moments, which are especially important for the dimensions of sections.

The results show that the system of reciprocal linkages makes it possible to achieve flat meshes that are strong and effective. They also permit the construction of meshes that would be mechanisms if they were made using articulated linkages. This is the case with the flat mesh that uses reciprocal linkages which become braced in their final position, without the need for supplementary bars or external constraints.

These results show excellent behaviour. The diagrams are practically lineal, and there is hardly any residual deformation. On the other hand, the residual deformation in question permits the readjustment of a deployable structure under load. In all of the tests previous steps of loading were applied to prevent this readjustment from affecting the measurement results.

The use of reciprocal linkages gives rise to more than $90 \%$ degree of embedment in the end of the bars for usual dimensions, so that the structure deforms less. It also considerably reduces the most unfavourable bending moments, so that the necessary cross-sections can also be reduced. The result is a simpler structure that is more economical and offers better performance.

The use of reciprocal linkages prevents the angle between the bars from surpassing their angle of prolongation. This means that the structure can only fold in the correct direction, thereby facilitating this process.

Flat deployable structures with articulated linkages have hardly been used because of their high degree of deformability. Nevertheless, they have major advantages, as they are completely regular and all of their bars are the same length, so that they are simpler to make and erect. The use of reciprocal linkages substantially increases their strength and rigidity, making the use of flat meshes viable. They also make it possible to design other types of meshes, such as domes, vaults, gable roofs or hyperbolic paraboloid modules, while maintaining the advantages of reciprocal linkages.

The proposed solutions make it possible to design buildings that are suitable for the required uses. They can be used as emergency housing, although they are better suited for use as community facilities with longer spans, such as canteens, schools or religious buildings, etc. Constructions of this type are especially suitable for these community uses, so they will be studied in depth. This line of research is particularly interesting at the present time, as it is being followed worldwide.

\section{ACKNOWLEDGEMENTS}

This study is part of the research project "Deployable and modular constructions for situations of humanitarian catastrophe", funded by the Ministry of Economy and Competitiveness of the Kingdom of Spain with reference BIA2016-79459-R. 


\section{REFERENCES}

[1]. Pérez Piñero, E. 1968. Estructures reticulées. "L'Architecture d'Aujourd'hui". Vol. 141. pp. 76-81.

[2]. Pérez Piñero, E. 1961. "Estructura reticular estérea plegable". Spanish Patent 266801.

[3]. Pérez Belda, E, Pérez Almagro, C. 2016. "The deployable architecture commemorates the 25 years of peace. 50 th Anniversary of Emilio Pérez Piñero's Pavilion" EGA Num.28. doi: 10.4995/ega.20166307.

[4]. Escrig Pallares, F. y Pérez-Valcárcel, J. 1988. " Estructuras espaciales desplegables curvas" Informes de la Construcción, Vol. 39 n 393.

[5]. Escrig Pallares, F. y Sánchez Sánchez, J. 1999. " Estructura plegable de malla para la cubrición de recintos." Patente 2158787 A1.

[6]. Pérez-Valcárcel, J.; Escrig, F.; Martín, E.; Vázquez, J.A. 1995. "Analysis of expandable domes of squared modulus with self-folding roofing plates". Int. Conference on Spatial Structures: Heritage, present and future IASS. Milán. Vol 2. pp 551-558.

[7]. Pérez-Valcárcel, J.; Escrig, F.; Estévez, J.; Martín, E. "Large Span Expandable Domes". Int. Conference on Large Span Structures. Toronto. 1992. Vol 2. pp 619-630.

[8]. Gantes, C.; Connor, J.J.; Logcher, R.D. 1991. Combining Numerical Analysis and Engineering Judgement To Design Deployable Structures. "Computers \& Structures". Vol. 40. № 2, pp.431-440.

[9]. Pellegrino, S. 2001. Deployable Structures. Springer.

[10]. Pérez-Valcárcel, J.; Escrig, F.; Domínguez,E., Lamas, V. 1999. Expandable Structures with Selffolding Stiffeners. "Int Conference on Shells ans Spatial Structures: From recent past to the next millenium IASS". Madrid. 1999. Vol 2. pp D21, D30.

[11]. Escrig, F.; Pérez-Valcárcel, J. 1996. Deployable Cover on a Swimming Pool in Seville. "Bulletin of the International Association for Shell and Spatial Structures". Vol 37. № 120 pp 39-70.

[12]. De Temmerman N. Design and analysis of deployable bar structures for mobile architectural applications. [Ph. D. Thesis]. Brussels: Vrije Universiteit Brussels; 2007.

[13]. Roovers, K.; De Temmerman, N., Deployable scissor grids consisting of translational units. International Journal of Solids Structures, Vol. 121, 2017, pp. 45-\{)1. [DOI: 10.10 16/j.jijsolstr.20 17.05.015]

[14]. Arnouts, Liesbeth; Massart, J.; De Temmerman, Niels; Berke, Péter 2018. "Computational modelling of the transformation of bistable scissor structures with geometrical imperfections". Engineering Structures. Volume 177, Pages 409-420. DOI: 10.1016/j.engstruct.2018.08.108.

[15]. Gantes CJ. Deployable structures: analysis and design. Boston: WIT Press; 2001.

[16]. Yenal Akgün, Charis J. Gantes, Werner Sobek, Koray Korkmaza, Konstantinos Kalochairetis. A novel adaptive spatial scissor-hinge structural mechanism for convertible roofs. Engineering Structures 33 (2011) 1365-1376.

[17]. Lara Alegria Mira, Ashley P. Thrall, Niels De Temmerman "Deployable scissor arch for transitional shelters". Automation in Construction. Volume 43, July 2014, Pages 123-131. doi.org/10.1016/j.autcon.2014.03.014

[18]. Lara Alegria Mira, Ashley P. Thrall, Niels De Temmerman "Construction of a deployable scissor arch for shelters". International Conference Transformables 2013. Sevilla, España. 2013. pp 93-98. Escrig y Sánchez (Ed.) () 2013 Starbooks, Sevilla, ISBN 978-84-939565-3-0.

[19]. Begiristain Mitxelena J. Sistemas estructurales desplegables para infraestructuras de intervención urbana autoconstruidas. [Ph. D. Thesis]. San Sebastián: Universidad del País Vasco; 2015.

[20]. Maden, F. Novel design methodologies for transformable doubly-ruled surface structures. [Ph. D. Thesis]. Izmir Institute of Technology; 2015. 
[21]. Arash Osmani, Mohammad Reza Matini, Yaser Shahbazi, Hossein Golabi. Hyperbolic paraboloid (hp) pantographic structure with liner scissors. 2017. Architecture Civil Engeenering Environment. No. 4/2017. 89-99 DOI: 10.21307/acee-2017-052

[22]. Hoberman, C. 1992. The Art \& Science of Folding Structures. Sites Architecture.

[23]. Choo,B.; Couliette, P. \& Chilton, J. 1994. "Retractable roof using the Reciprocal Frame". Proceedings of IABSE Symposium (Birmingham): Places of assembly and long-span building structures.

[24]. Sánchez, J.; Escrig, F. \& Rodríguez, $M^{\mathrm{a}}$ T. 2010. "Reciprocal frames designed by Leonardo. An analytical approach", Informes de la Construcción. Vol. 62, 518, 5-14, DOI: 10.3989/ic.09.032

[25]. Popovič Larsen, O. 2014. "Reciprocal Frame (RF) Structures: Real and Exploratory", Kim Williams Books, Turin. Nexus Network Journal. DOI 10.1007/s00004-014-0181-0

[26]. Popovič, O.; Sang-Hoon, D. "Reciprocal Frames (RFs) Used for Quick-built Deployable Emergency Shelters". Proceedings of the International Association for Shell and Spatial Structures (IASS) Symposium 2013.

[27]. Yenal Akgün Y., Gantes C., Sobekd W., Korkmaza K., Kalochairetis K. A novel adaptive spatial scissor-hinge structural mechanism for convertible roofs. Engineering Structures 33 (2011) 13651376.

[28]. Pérez-Valcárcel, J. et al. 2018.“Estructura desplegable, edificación y método de construcción de una edificación" Spanish Patent P201831054.

[29]. Freire-Tellado, M. J.; Muñoz-Vidal, M.; López-César, I.; Pérez-Valcárcel, J. (2019). Estructuras desplegables de aspas para cubiertas inclinadas. Informes de la Construcción, 71(556): e311. https://doi.org/10.3989/ic.64120.

[30]. Pérez-Valcárcel, J.; Escrig, F. (1987) Bases del cálculo no lineal de estructuras desplegables espaciales "Boletín Académico de la ETSA de La Coruña", num. 7. Pp 36-40.

[31]. Pérez-Valcárcel, J.; Escrig, F.; Martín, E.; Domínguez, E.; Jaureguizar, F. "Recent advances in analysis of expandable structures: An improved method". 1998. Int. Conference on Spatial Structures in New and Renovation Projects of Building and Construction IASS. Moscú. Vol 1. pp 192-199. 